\title{
An impossible task?
}

\author{
The Paris Agreement on climate change has shifted international focus to more stringent mitigation, and \\ asked the scientific community to work out what that means on a tight timeline. The challenge is steep, \\ but well worth a go.
}

Not for the first time, a meeting of policymakers has thrown the climate research community into some turmoil. The Paris Agreement ${ }^{1}$ affirms the canonical goal of limiting warming to no more than $2{ }^{\circ} \mathrm{C}$ above pre-industrial levels, but it also states the aim to pursue a warming limit as low as $1.5^{\circ} \mathrm{C}$. With this addition, a new question entered centre stage: how much of a difference does the extra half a degree of mitigation effort make, both in terms of permissable emissions and in terms of potential impacts? This question was referred back to the scientific community in the form of an invitation to the Intergovernmental Panel on Climate Change (IPCC) to provide a Special Report in 2018. Climate researchers seem keen to help: at Nature Geoscience we are already seeing heightened interest in exploring a $1.5^{\circ} \mathrm{C}$ world. A Commentary on page 187 of this issue outlines some of the key points that need the attention of geoscientists.

The original $2^{\circ} \mathrm{C}$ target had evolved through the Copenhagen Accord in 2009 as a political compromise between the desirable and the achievable, and caused extensive discussions among climate scientists - for example, whether global mean surface temperatures are an adequate measure of climate change - that are just beginning to settle $^{2}$. But now the Paris Agreement has set the sights of governments on a $1.5^{\circ} \mathrm{C}$ world.

The task of teasing out differences between these two targets is by no means easy. The emissions side of the question is not straightforward, even though cumulative budgets of allowable carbon dioxide emissions can be quantified with some confidence for any given temperature target ${ }^{3}$. Any realistic pathway to a $1.5^{\circ} \mathrm{C}$ world will probably require an initial overshoot beyond the temperature target and the subsequent removal of significant amounts of carbon dioxide from the atmosphere ${ }^{4}$, which may turn out to be unfeasible. The ambition to limit anthropogenic warming is also complicated by the warming effects of greenhouse gases other than $\mathrm{CO}_{2}$, of aerosols and of albedo changes, which act on a variety of time horizons and spatial scales and are less well studied. These contributions to warming will need to be factored into a temperature-based target.

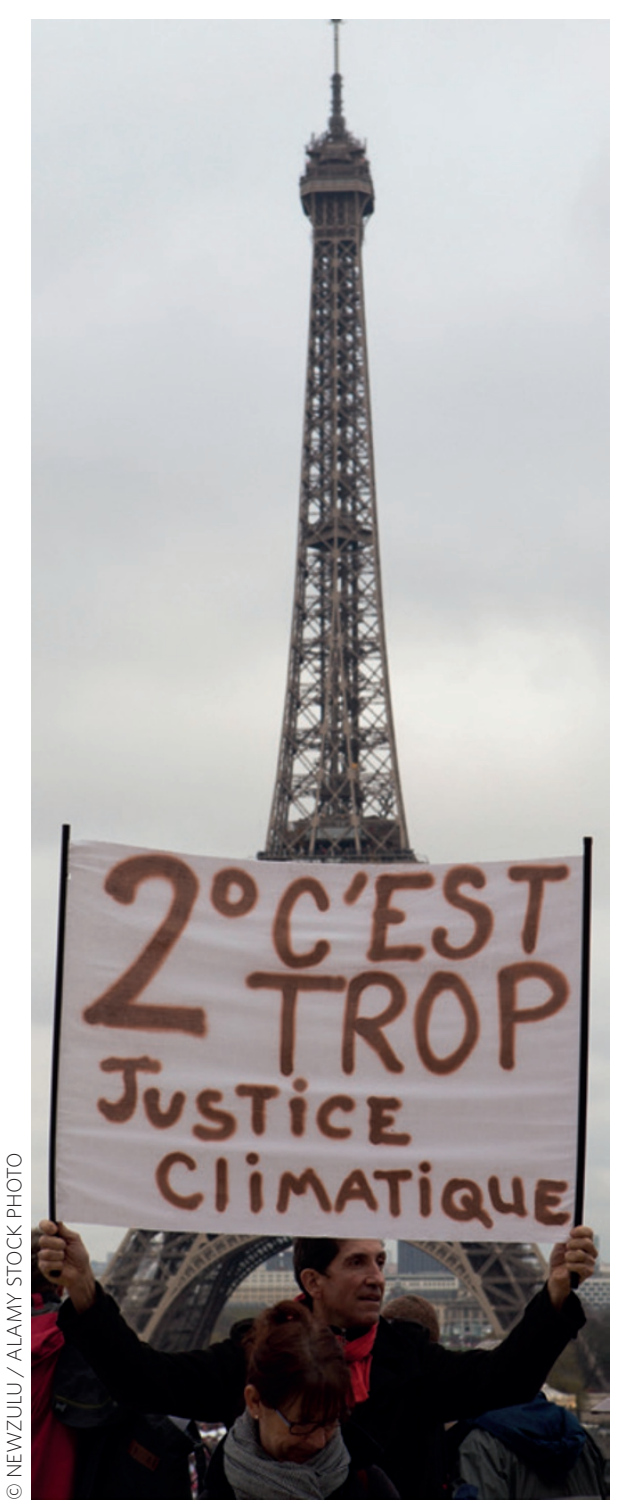

On the impacts side, the picture is not clear either - even without considering potential irreversible impacts resulting from an overshoot of the $1.5^{\circ} \mathrm{C}$ target ${ }^{5}$. To be clear, a $1.5^{\circ} \mathrm{C}$ world will almost certainly look very different from a world at $2{ }^{\circ} \mathrm{C}$. The problem is not that there is no difference, but that internal variability and differences between model projections make the uncertainties so large that it is hard to say with confidence what exactly these differences will look like.
As a result, projections for key climate variables, such as temperature and precipitation, do not show obvious, societally important differences in their global mean amplitudes or patterns between a 1.5 and $2{ }^{\circ} \mathrm{C}$ world ${ }^{2}$. Indeed, it has been argued ${ }^{6}$ that we may not know enough to clearly distinguish differences between the two target warming levels after uncertainties are taken into account by the time of the requested 2018 IPCC assessment.

However, the task may not be impossible. In some regions, such as the Mediterranean, the contiguous United States and central Brazil, warming is greater than global mean surface temperature rise, and the signal is therefore amplified. For example, relative to $1861-1880$, we would expect annual maximum temperatures to rise by $2.2^{\circ} \mathrm{C}$ in the Mediterranean region in a $1.5^{\circ} \mathrm{C}$ world, compared to more than $3{ }^{\circ} \mathrm{C}$ in a $2{ }^{\circ} \mathrm{C}$ world 7 . Another avenue for quantifying the gains from more stringent mitigation could be to shift our focus towards discussing risks avoided rather than trying to pin down benefits we are confident about. The risks for most impacts will be discernibly higher in a $2{ }^{\circ} \mathrm{C}$ world than at half a degree less.

Obviously, climate researchers should not abandon their other pursuits, including curiosity-driven research, in order to lend their services to policymakers. But it is worth diverting some attention to the tasks mapped out in Paris. A wealth of studies and climate model simulations already exists that can be re-examined with a new focus on understanding the full implications of a $1.5^{\circ} \mathrm{C}$ world. They deserve to benefit from all the ingenuity that the climate science community can muster.

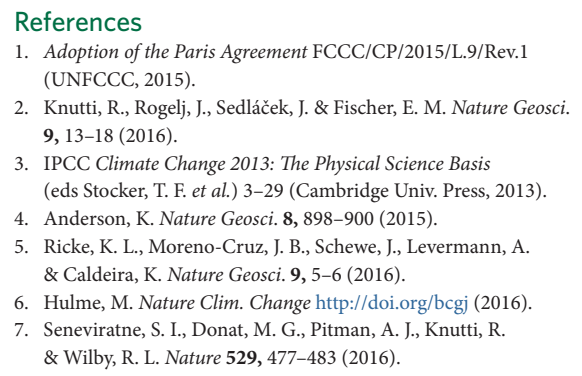

2. Knutti, R., Rogelj, J., Sedláček, J. \& Fischer, E. M. Nature Geosci. 9, 13-18 (2016).

3. IPCC Climate Change 2013: The Physical Science Basis (eds Stocker, T. F. et al.) 3-29 (Cambridge Univ. Press, 2013).

4. Anderson, K. Nature Geosci. 8, 898-900 (2015).

5. Ricke, K. L., Moreno-Cruz, J. B., Schewe, J., Levermann, A. \& Caldeira, K. Nature Geosci. 9, 5-6 (2016).

6. Hulme, M. Nature Clim. Change http://doi.org/bcgj (2016).

7. Seneviratne, S. I., Donat, M. G., Pitman, A. J., Knutti, R. \& Wilby, R. L. Nature 529, 477-483 (2016). 